\title{
Washington Teleconferencing Program
}

\author{
William O. Robertson, MD, FACMT, FAAPa
}

aMedical Director, FACMT, FAAP, Washington Poison Center, Seattle, WA

In this recent age of free long distance and telephony, it is hard to imagine that 14 years ago we technology deprived toxicologists in Washington started each week with a lively one hour 8:30 a.m. teleconference that included associate medical directors in Seattle, Tacoma, Spokane, and even Boise, Idaho. This program was the serendipitous result of the consolidation of our state's four regional poison centers in 1993 [1]. We decided to take advantage of our widely scattered experts in the region. Staff moved to Seattle from Spokane and Tacoma to become employees of the consolidated Washington Poison Center, but prior medical directors who were boarded in Medical Toxicology remained in their communities. Taking advantage of electronic paging (beepers-and later, cell phones), we made prior medical directors Associate Medical Directors for the Center and arranged a rotating weekly call-schedule for them to serve as back-up for the Center. Each received a modest stipend along with appropriate no-charge malpractice coverage and the understanding that, as emergency physicians, they were not to serve as back-up medical toxicologists at the same time. When they were on duty, the Medical Director would take over.

At that time, we took advantage of our experiences with teleconferencing, which had been used for Continuing Medical Education in Washington for more than 30 years. By teleconferencing, I am referring exclusively to the use of audio devices, such as telephones. In 1984, we reported our use of the teleconferencing technique of continuing education in rural Idaho. As many as 300 listeners participated in a teleconference at a cost of $<\$ 2.00$ per individual attendee [2]. With a central speakerphone, a tape recorder, and a conference bridge via Emergency Services in Idaho, the Monday morning weekly teleconference has been in session since September 1993. Its primary purpose is to review the prior week's caseload and the more complicated clinical problems. The recorded tapes are made available to the entire staff for their review as part of our regular in-service program.

The weekly conference is intended to last one hour with the focus on new business that involves the centers as well as interesting and different cases - copies of which have already been distributed to the on-call Associate Medical Director at his or her site as well as to the Medical Director here in Seattle. The on-call Associate Medical Director is responsible for selecting the more detailed cases; the Medical Director also reviews the week's load and also selects and presents 6 to 10 hot newspaper clippings relevant to the field of toxicology: routine, controversial, and new business from the American Association of Poison Control Centers (AAPCC), the Health Resources and Services Administration (HRSA), the State of Washington's Department of Health, the Bioterrorism Scene, and others are included as well as 5 to $10 \mathrm{sci}-$ entific journal articles that come from sources other than the standard journals toxicologists tend to read.

Subsequently, the Medical Director prepares minutes and, along with copies of the above news items, mails a copy to each of the Associate Medical Directors and posts them on the Communication Clipboard in the in-house Call Center for the staff to peruse. Because the conference lasts only an hour, the journal articles are simply mentioned as they are distributed for follow-up discussion on the local scene.

For any program to be a success, one must assess the staff's reaction to this teleconference program. Last year, we mailed out a simple one-page questionnaire to all 10 of the Associate Medical Toxicologists on our weekly conference call. In addition we encouraged on-line staff members $(\mathrm{N}=20)$ at the Center to respond. All 10 medical toxicologists and 10 of 20 call center staff responded to the survey. Seven out of the 10 toxicologists liked the time of day: the earlier the better for work but not for

Keywords: teleconferencing, community poisoning, poison treatments

Notes: There was no outside funding of any kind used for this study.

Corresponding Author: William O. Robertson, MD, Medical Director, Washington Poison Center, 155 NE $100^{\text {th }}$ Street, \#400, Seattle, WA 98125.

Email:mryuk@wapc.org 
family; three toxicologists with children found it problematic. Better and longer-term follow-up was the most sought addition; 9 out of 10 encouraged continuing the newspaper clippings; all valued the center updates. Several asked for more about what was happening in D.C. with AAPCC and with the Feds-in particular, the HRSA and the Food and Drug Administration (FDA). Although case reviews proved the most popular item of discussion, there was a plea for more detailed follow-up, particularly for long-term outcomes. Moreover, all 10 reviewed the journal material, but 4 were candid in admitting that it was simply too much to read. The call center staff expressed comparable opinions to the toxicologists, with both groups strongly supporting the interchanges and differences of opinion so well expressed about the individual cases. Some of these interactions were eventually incorporated into our up-dated guidelines. As an aside, we do not employ any protocols except as components of research undertakings where compliance is intended to be $100 \%$. In contrast, we use guidelines that are intended to be susceptible to clinical modifications.

Initially, we limited teleconference participation to our medical directors in Seattle, Tacoma, Spokane, and Boise, Idaho. We subsequently expanded participation to include Oregon. As the regionalization process seems to be evolving, our Center and the Oregon center are in virtually daily contact about a host of matters. Washington and Oregon poison centers get funding from their own state legislature. And when it comes to appearing before our respective legislatures, both state centers agree that there is real advantage to be seen as citizen voters from our respective states. While we wrestle with the Homeland Security issues, the general theme of local representation is also highly regarded, regardless of scientific data to the contrary. We let our legislatures know that we partner on a host of programs, including HRSA funds where we have been consolidated.

In the last several years, our teleconference has expanded tremendously beyond the Pacific Northwest to include almost 10 states. New additions include New Jersey, Nebraska, Montana, and Wyoming, an individual in Tucson, Arizona, and another in Anchorage, Alaska. Two of these states do not have poison centers, and these listeners are most helpful participants. Another participant is in a state that does have a center, but the director's heritage is with ours and so he still works for us. In addition, Medical Directors and staff members from New Jersey and Nebraska Poison Centers have joined us to share their interesting cases. And sometimes we have participants from the British Columbia Poison and Drug Information Unit, and this adds an international spin to our efforts.

To date, our teleconferencing has exclusively been through the use of telephones. Typically, two-way communication is facilitated with multiple speakerphones. We have talked about using interactive television, but - to date-no one seems to think that the added effort and cost warrants implementation. With improved free telephony, such as Sight Speed ${ }^{\circledR}$ and Skype ${ }^{\circledR}$, this may be worth pursuing, especially with the video conferencing capability of these programs.

Any parties interested in listening to our weekly toxicology teleconference can simply call Dr. William O. Robertson at 1-206517-2356 or e-mail him at robertso@wapc.org. While our sample is somewhat less than likely to prove statistically accountable, our respondents have proven most enthusiastic about our ongoing teleconference sessions. And we plan to continue the sessions without any major modification other than attempting to improve the way we seek to gather longer follow-up. We urge other centers to try such teleconferences. You will find them useful and you will like them.

The author has no potential financial conflicts of interest to report.

\section{REFERENCES}

1. Robertson WO. Washington Poison Center's Weekly Teleconference. Health Clinical Toxicology. 2005;3(6):774.

2. Anderson P, Emerson D, Robertson WO. Delivering Educational Programs Via Telephone: Teleconferencing. Vet and Human Tox. 1984;26(Supplement \#2):14-15. 